\title{
Participação no cuidado em saúde: a voz da criança e do adolescente que vivem com HIV
}

\author{
Maria da Graça Corso da Motta \\ Enfermeira. Doutora em Enfermagem. Professora Titular do \\ Departamento de Enfermagem da Universidade Federal do Rio Grande do Sul \\ Daniela Dal Forno Kinalski \\ Enfermeira. Doutoranda do Programa de Pós-Graduação em \\ Enfermagem da Universidade Federal do Rio Grande do Sul \\ $\triangle$ daniela.kinalski@gmail.com \\ Vânia Schneider \\ Enfermeira. Doutoranda do Programa de Pós-Graduação em \\ Enfermagem da Universidade Federal do Rio Grande do Sul

\section{Bibiana Sales Antunes} \\ Enfermeira. Doutoranda do Programa de Pós-Graduação em \\ Enfermagem da Universidade Federal do Rio Grande do Sul

\section{Glaucia Tuise Evangelista} \\ Aluna do curso de enfermagem da Universidade Federal do Rio Grande do Sul \\ Vitoria Martins \\ Aluna do curso de enfermagem da Universidade Federal do Rio Grande do Sul
}

\begin{abstract}
Resumo:
A participação da criança e do adolescente na tomada de decisões emrelação ao seu cuidado emsaúde ainda é um tema pouco estudado. Essa realidade aponta para sua invisibilidade, apesar do seu desejo e do direito de serem ouvidos e de terem suas percepções, preferências e escolhas respeitadas nas decisões emrelação ao seu corpo e a sua saúde. O objetivo do presente artigo é identificar asevidências científicas acerca de como as crianças e os adolescentes que vivem comHIV participamna tomada de decisões em relação ao seu cuidado em saúde. Procedeu-se a uma revisão integrativa, realizada no período de janeiro a maio de 2019, nas seguintes bases de dados eletrônicas:LILACS, PubMed e Scopus. Localizaram-se 5308 produções, das quais forammencionadas nove neste trabalho. A partir da análise dos artigos selecionados, constatou-se que as crianças e os adolescentes que vivem comHIV têmvoz no seu cuidado emsaúde, de modo secundário, emrelação a três aspectos:à informação, à autonomia e às decisões em relação ao seu cuidado em saúde. As evidências científicas revelam que essa população participa da tomada de decisões emrelação ao seu cuidado em saúde emaspectos pontuais, ou seja, em estratégias de cuidado necessárias a quem vive com HIV.Conclui-se que os profissionais da saúde devemreconhecer a criança e o adolescente que vivem com HIV como protagonistas do seu cuidado em saúde, a fim de levá-los a aderir ao tratamento, melhorando a eficácia deste e, consequentemente, seu bem-estar.

Palavras-chave:HIV , Síndrome de Imunodeficiência Adquirida, Defesa da Criança e do Adolescente, Criança, Adolescente.
\end{abstract}




\title{
Participation in health care: the voice of children and adolescents living with HIV
}

\begin{abstract}
:
The participation of children and adolescents in decision-making in relation to their health care is still a poorly studied topic. This reality points to their invisibility, despite their desire and the right to be heard and to have their perceptions, preferences and choices respected in decisions regarding their body and their health. Given this reality, the objective of this article is to identify the scientific evidence about how children and adolescents living with HIV participate in decision-making in relation to their health care. An integrative review was carried out, fromJanuary to May 2019, in the following electronic databases:LILACS, PubMed and Scopus. 5308 productions were found, of which nine were mentioned in this work. From the analysis of the selected articles, it was found that children and adolescents living with HIV have a voice in their health care, in a secondary way, in relation to three aspects: information, autonomy and decisions regarding the your health care. Scientific evidence reveals that this population participates in decision-making regarding their health care in specific aspects, that is, in care strategies necessary for those living with HIV. It is concluded that health professionals must recognize children and adolescents living with HIV as protagonists of their health care, in order to satisfy them in relation to treatment, improve their adherence and well-being. Keywords: HIV, Acquired Immunodeficiency Syndrome, Child and Adolescent Defense, Child, Adolescent.
\end{abstract}

\section{Participación en la atención médica: la voz de los niños y adolescentes que viven con el VIH}

\section{Resumen:}

La participación del niño y del adolescente en la toma de decisiones en relación con su atención médica todavía es un tema poco estudiado. Esa realidad sugiere su invisibilidad, a pesar de su deseo y de su derecho a ser escuchados y a que se respeten sus percepciones, preferencias y elecciones en las decisiones relacionadas con su cuerpo y su salud. Dada esa realidad, el objetivo del presente artículo es identificar las evidencias científicas sobre cómo los niños y los adolescentes que viven con el VIH participan en la toma de decisiones en relación con su atención médica. Se realizó una revisión integradora, desarrollada de enero a mayo de 2019, en las siguientes bases de datos electrónicas: LILACS, PubMed y Scopus. Se encontraron 5308 producciones, de las cuales nueve fueron referenciadas en este trabajo. A partir del análisis de los artículos seleccionados, se descubrió que los niños y los adolescentes que viven con el VIH tienen voz en su atención médica, de manera secundaria, en relación con tres aspectos: información, autonomía y decisiones con respecto a su cuidado de la salud. Las evidencias científicas revelan que esta población participa en la toma de decisiones con respecto a su atención médica en aspectos específicos, es decir, en las estrategias de atención necesarias para las personas que viven con el VIH. Se concluye que los profesionales de la salud deben reconocer al niño y al adolescente que viven con el VIH como protagonistas de su atención médica, para que se adhieran al tratamiento, mejorando su efectividad y, en consecuencia, su bienestar.

Palabras clave: VIH, Síndrome de Inmunodeficiencia Adquirida, Defensa del Niño y del Adolescente, Niño, Adolescente.

\section{INTRODUÇÃO}

A participação da criança e do adolescente na tomada de decisões em relação ao seu cuidado em saúde ainda é um tema pouco estudado (COYNE, 2008; COYNE et al., 2014; 
OLSZEWSKI; GOLDKIND, 2018). Essa realidade aponta para sua invisibilidade, apesar do seu desejo e do direito de serem ouvidos e de terem suas percepções, preferências e escolhas respeitadas nas decisões em relação ao seu corpo e a sua saúde (COYNE et al., 2016; ELER; ALBUQUERQUE, 2019a, 2019b; HEIN et al., 2015).

A Convenção dos Direitos da Criança (CDC) (1989) ${ }^{1}$, adotada pela Organização das Nações Unidas (ONU), reconhece a participação da criança e do adolescente como um direito humano. O artigo $\mathrm{n}^{\circ} 12$ assegura sua participação, respeitando sua idade e sua maturidade, e o comentário geral no 12 (ONU, 2009) vem subsidiar, nas diferentes instâncias e dimensões da vida (família, escola e serviços de saúde), a implementação de políticas e práticas que possibilitem a voz da criança e do adolescente em seu cuidado em saúde (ELER; ALBUQUERQUE, 2019a).

A voz da criança e do adolescente é compreendida como a liberdade de consentir e opinar sobre os processos diagnósticos e terapêuticos, assim como de optar pelo seu acompanhante aos serviços de saúde (CARNEVALE, 2012; CARNEVALE et al., 2014). Por vezes, a tomada de decisão é realizada por profissionais ou responsáveis de forma unilateral, não respeitando a autonomia, o direito (KONDER; TEIXEIRA, 2016) e as possibilidades de participação da criança e do adolescente nos cuidados em saúde (COYNE et al., 2014).

Nessa perspectiva, atentando para o aumento global da prevalência de crianças e de adolescentes que vivem em condições crônicas, exige-se uma reflexão dos profissionais sobre como a participação no cuidado em saúde está constituída nos serviços de saúde e na família (OLSZEWSKI; GOLDKIND, 2018). Dentre as condições crônicas, destacam-se a infecção pelo Vírus da Imunodeficiência Humana (HIV) e o adoecimento pela síndrome da Imunodeficiência Adquirida (Aids).

Nos direitos humanos, a CDC e, principalmente, o comentário geral no 3 defendem a importância da participação da criança e do adolescente que vivem com HIV nas decisões em relação ao seu cuidado em saúde (ONU, 2003), frente às demandas e implicações do viver uma condição crônica. O crescer e o viver com HIV se tramam em temas fundantes para o cuidado

\footnotetext{
${ }^{1}$ Ao trabalharmos com a população de crianças e adolescentes que vivem com HIV, é imprescindível classificálos. Assim, perante a CDC, no seu art.1, criança é todo ser humano menor que 18 anos (ONU, 1989). No Estatuto da Criança e do Adolescente (ECA) define que todo ser humano até os 12 anos incompletos é considerado criança e até os 18 anos é considerado adolescente (BRA SIL,1990). Neste estudo, optou-se pela normativa de classificação do ECA.
} 
em saúde, como o diagnóstico da infecção; a revelação do diagnóstico; a adesão ao tratamento; a sexualidade, a saúde sexual e reprodutiva; a transição do cuidado; entre outros (BRAGA et al., 2016).

Assim, este estudo tem como objetivo identificar as evidências científicas acerca de como as crianças e os adolescentes que vivem com HIV participam na tomada de decisões em relação ao seu cuidado em saúde.

\section{MÉTODO}

Trata-se de uma revisão integrativa da literatura que tem como propósito sistematizar e sintetizar evidências a respeito de um determinado problema de pesquisa (MENDES; SILVEIRA; GALVÃO, 2008). A busca das produções científicas foi realizada nas bases eletrônicas de dados Literatura Latino-Americana e do Caribe em Ciências da Saúde (LILACS), Public MEDLINE (PubMed) e SciVerse Scopus (Scopus). Neste estudo, seguiram-se seis (6) etapas metodológicas, que serão descritas a seguir (MENDES; SILVEIRA; GALVÃO, 2008).

A primeira etapa foi constituída pela elaboração da questão de revisão: "Quais as evidências científicas acerca de como as crianças e os adolescentes que vivem com HIV participam na tomada de decisões em relação ao seu cuidado em saúde?". Para sua elaboração, utilizou-se a estratégia PICo: P (População): crianças e adolescentes que vivem com HIV; I (Interesse): participação na tomada de decisões; Co (Contexto): cuidado em saúde.

Na segunda etapa, os critérios de inclusão foram: artigos científicos nos idiomas português, inglês ou espanhol, oriundos de pesquisa original, referente à temática, disponíveis na íntegra e publicados nos últimos cinco anos, considerando a magnitude de publicações que envolvem o tema HIV. Para a busca na íntegra, foram acessadas as bases de dados, o portal da Coordenação de Aperfeiçoamento de Pessoal de Nível Superior e a página do periódico correspondente. Para o acesso a artigos não disponíveis online, foi contatado o autor principal, e os artigos encontrados em mais de uma base de dados foram considerados para seleção e análise apenas uma vez.

As estratégias utilizadas estão descritas no Quadro 1. Dois revisores realizaram a busca, simultaneamente, de janeiro a maio de 2019, com a finalidade de evitar o viés de 
seleção dos artigos. Ao encontrar divergências na elegibilidade, optou-se por consenso ou pela avaliação de um terceiro revisor com experiência no tema.

Quadro 1 - Estratégias utilizadas nas bases de dados LILACS, PubMed e SCOPUS. Porto Alegre/RS, 2020.

\begin{tabular}{|c|c|}
\hline $\begin{array}{c}\text { BASE } \\
\text { DE } \\
\text { DADOS }\end{array}$ & ESTRATÉGIAS \\
\hline LILACS & $\begin{array}{l}\text { ("virus da imunodeficiencia humana") or "sindrome da imunodeficiencia adquirida" [descritor de } \\
\text { assunto] and ("criança") or "saude da crianca" [descritor de assunto] e ("virus da imunodeficiencia } \\
\text { humana") or "sindrome da imunodeficiencia adquirida" [descritor de assunto] and ("adolescente") } \\
\text { or "saude do adolescente" [descritor de assunto]. }\end{array}$ \\
\hline PubMed & $\begin{array}{l}\text { (human immunodeficiency virus } 1 \text { [MeSHTerms]) OR human immunodeficiency virus } 2 \\
\text { [MeSHTerms]) OR acquired immunedeficiency syndrome [MeSHTerms]) AND children } \\
\text { [MeSHTerms] e (human immunodeficiency virus } 1 \text { [MeSHTerms]) OR human immunodeficiency } \\
\text { virus } 2 \text { [MeSHTerms]) OR acquired immunedeficiency syndrome [MeSHTerms]) AND adolescent } \\
\text { [MeSHTerms]. }\end{array}$ \\
\hline SCOPUS & $\begin{array}{l}\text { (TITLE-ABS-KEY ("human immunodeficiency virus 1") OR TITLE-ABS-KEY ("human } \\
\text { immunodeficiency virus 2") OR TITLE-ABS-KEY ("acquired immunedeficiency syndrome") AND } \\
\text { TITLE-ABS-KEY (adolescent) e (TITLE-ABS-KEY ("human immunodeficiency virus 1") OR TITLE- } \\
\text { ABS-KEY ("human immunodeficiency virus 2 ") OR TITLE-ABS-KEY ("acquired immunedeficiency } \\
\text { syndrome") AND TITLE-ABS-KEY (children). }\end{array}$ \\
\hline
\end{tabular}

Fonte: elaborado pelos autores. Porto Alegre/RS 2020.

$\mathrm{Na}$ busca, foram encontradas 5.308 produções científicas na totalidade, sendo as duplicadas consideradas apenas uma vez, totalizando 5.222 produções para a aplicação dos critérios de inclusão. Elegeram-se 51 artigos para leitura na íntegra, dos quais nove foram incluídos no corpus do estudo. A Figura 1 ilustra o fluxograma da seleção dos artigos para a revisão integrativa, baseado no modelo PRISMA (MOHER et al., 2009).

A terceira etapa constitui-se pela extração dos dados. Utilizou-se uma planilha no Microsoft Excel composta pelas seguintes informações: título, periódico, autores, ano de publicação, objetivo, delineamento (abordagem, participantes), nível de evidência, participação da criança e do adolescente que vivem com HIV na tomada de decisões em relação ao seu cuidado em saúde. 
Figura 1: Fluxograma da seleção dos artigos para a revisão integrativa, baseado no modelo PRISMA. Porto Alegre, 2020.
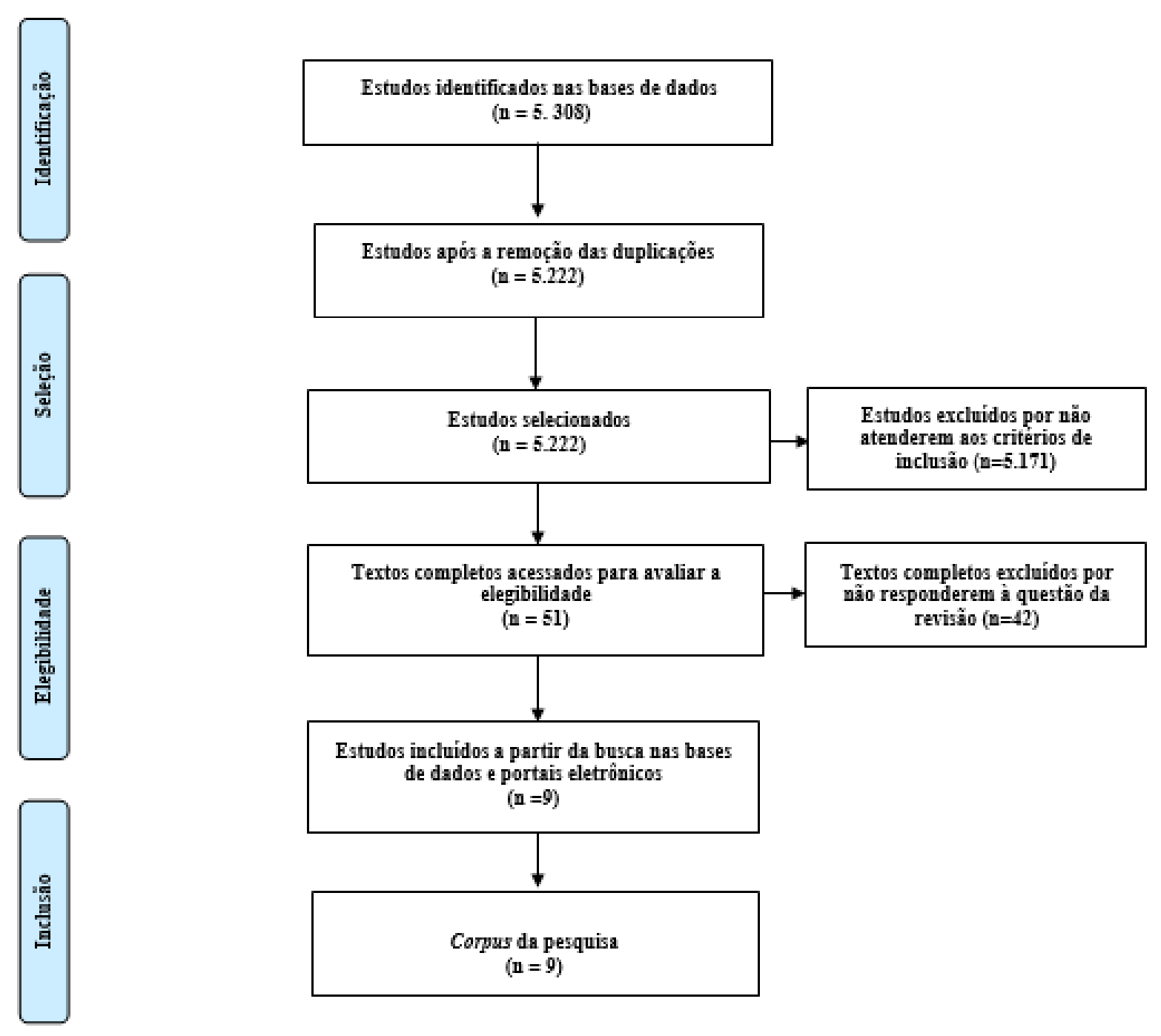

Fonte: elaborada pelos autores. Porto Alegre/RS, 2020.

A quarta etapa - avaliação crítica dos artigos selecionados - deu-se por meio da classificação do nível de evidência, considerando o tipo de questão clínica do estudo primário. Quando a questão é de tratamento/intervenção, tem uma classificação hierarquizada em sete níveis; de prognóstico/etiologia em cinco níveis; e de significado/experiência/compreensão do usuário em cinco níveis. 
A interpretação dos resultados, desenvolvida na quinta etapa, foi pautada na resposta da questão da revisão. Na apresentação, que corresponde à sexta etapa, compreendeu-se a síntese do conhecimento e desenvolveu-se a categorização acerca da participação da criança e do adolescente que vive com HIV na tomada de decisões em relação ao seu cuidado em saúde.

Os preceitos éticos foram mantidos, respeitando-se os direitos autorais, mediante a citação dos autores.

\section{RESULTADOS}

$\mathrm{Na}$ caracterização quanto à procedência das produções científicas, identificou-se que $55,5 \%(n=5)$ concentram-se no Brasil. Em relação à área do conhecimento do primeiro autor das publicações, 33,3\% $(n=3)$ foram desenvolvidas por enfermeiros ou por equipe multiprofissional. A distribuição temporal demonstra uma concentração de 55,5\% (n = 5) das publicações no ano de 2015.

Para a síntese das produções analisadas, foi desenvolvido um quadro sinóptico (Quadro 2). Referente ao delineamento, predominaram estudos qualitativos em $77,8 \%$ dos estudos (n = 7); quanto à população, predominou a de adolescentes que vivem com HIV, representando $77,8 \%(\mathrm{n}=7)$. No que tange ao nível de evidência, 66,7\% $(\mathrm{n}=6)$ das produções possuem nível 2, e 33,3\% ( $n=3)$ possuem nível 4, classificadas a partir das questões clínicas relacionadas ao significado. 
Quadro 2 - Corpus da revisão integrativa. LILACS, PubMed e Scopus. Porto Alegre/RS,2020.

\begin{tabular}{|c|c|c|}
\hline OBJETIVOS & MÉTODOS & $\mathrm{NE} / \mathrm{QC}$ \\
\hline $\begin{array}{l}\text { Investigar o processo de estigma e discriminação em crianças com } \\
\text { HIV e Aids e suas consequências na adesão ao tratamento sob uma } \\
\text { perspectiva bioética (CONDE HIGUERA et al., 2016). }\end{array}$ & $\begin{array}{l}\text { Estudo qualitativo } \\
\mathrm{P}=11 \text { crianças de } 2 \\
\text { a } 13 \text { anos de idade. }\end{array}$ & N2/S \\
\hline $\begin{array}{l}\text { Relacionar a percepção de saúde do adolescente que vive com } \\
\text { HIV/Aids com possíveis estratégias para reduzir a propagação do } \\
\text { vírus (SEHNEM et al., 2015). }\end{array}$ & $\begin{array}{l}\text { Estudo qualitativo } \\
\mathrm{P} \quad 15 \\
\text { adolescentes. }\end{array}$ & $\mathrm{N} 2 / \mathrm{S}$ \\
\hline $\begin{array}{l}\text { Conhecer a partir da voz da criança que vive com HIV/Aids as } \\
\text { implicações na sua vida cotidiana (KUYAVA; RUBIM PEDRO, 2014). }\end{array}$ & $\begin{array}{l}\text { Estudo qualitativo } \\
\mathrm{P}=5 \text { crianças. }\end{array}$ & $\mathrm{N} 2 / \mathrm{S}$ \\
\hline $\begin{array}{l}\text { Analisar, através de entrevistas narrativas autobiográficas, como } \\
\text { jovens HIV positivas, infectadas por transmissão vertical, } \\
\text { constroem seus projetos de vida e, sobretudo, de maternidade } \\
\text { (EID; WEBER; PIZZINATO, 2015). }\end{array}$ & $\begin{array}{l}\text { Estudo qualitativo } \\
\mathrm{P}=3 \text { adolescentes. }\end{array}$ & N4/S \\
\hline $\begin{array}{l}\text { Compreender o significado da revelação do diagnóstico do Vírus } \\
\text { da Imunodeficiência Humana para o adolescente (BRUM et al., } \\
\text { 2015). }\end{array}$ & $\begin{array}{l}\text { Estudo qualitativo } \\
\mathrm{P} \quad 12 \\
\text { adolescentes. }\end{array}$ & $\mathrm{N} 2 / \mathrm{S}$ \\
\hline $\begin{array}{l}\text { Explorar o comportamento sexual e as características das } \\
\text { parcerias entre homens e mulheres HIV positivo em Zimbabwe } \\
\text { (MAVHU et al., 2018). }\end{array}$ & $\begin{array}{l}\text { Estudo qualitativo } \\
\mathrm{P}=28 \text { meninas } \\
\text { adolescentes. }\end{array}$ & $\mathrm{N} 2 / \mathrm{S}$ \\
\hline $\begin{array}{l}\text { Relatar as consequências do HIV/Aids no Caribe, especialmente na } \\
\text { população de crianças e adolescentes nascidos com HIV } \\
\text { (JOHNSON, 2018). }\end{array}$ & $\begin{array}{l}\text { Estudo de casos } \\
\mathrm{P}=1 \text { adolescente. }\end{array}$ & $\mathrm{N} 4 / \mathrm{S}$ \\
\hline $\begin{array}{l}\text { Explorar os significados atribuídos pelos jovens a "viver a } \\
\text { adolescência com o HIV" em um grupo de pacientes que adquiriu } \\
\text { a infecção no nascimento e os elementos implicados na adesão ao } \\
\text { tratamento antirretroviral (GALANO et al., 2016). }\end{array}$ & $\begin{array}{l}\text { Estudo qualitativo } \\
P=20 \text { adolescentes } \\
\text { e jovens. }\end{array}$ & N2/S \\
\hline $\begin{array}{l}\text { Avaliar os fatores que influenciam a Terapia Antirretroviral } \\
\text { (TARV) entre adolescentes infectados pelo HIV por meio da } \\
\text { transmissão vertical na Tailândia (XU et al., 2017). }\end{array}$ & $\begin{array}{l}\text { Estudo quanti- } \\
\text { qualitativo } \\
\mathrm{P} \quad=\quad 568 \\
\text { adolescentes. }\end{array}$ & N4/S \\
\hline
\end{tabular}

Legenda: (NE) Nível de evidência; (QC) Questão Clínica; (S) Classificação a partir das questões clínicas relacionadas ao significado.

Fonte: elaborado pelos autores. Porto Alegre/RS, 2020.

As evidências permitiram identificar que crianças e adolescentes que vivem com HIV têm voz no seu cuidado em saúde, de modo secundário, em relação a três aspectos: à informação; à autonomia e às decisões em relação ao seu cuidado em saúde (Figura 2). 
Figura 2: Evidências acerca da voz da criança e do adolescente que vive com HIV. LILACS, PubMed, Scopus. Porto Alegre/RS, 2020.

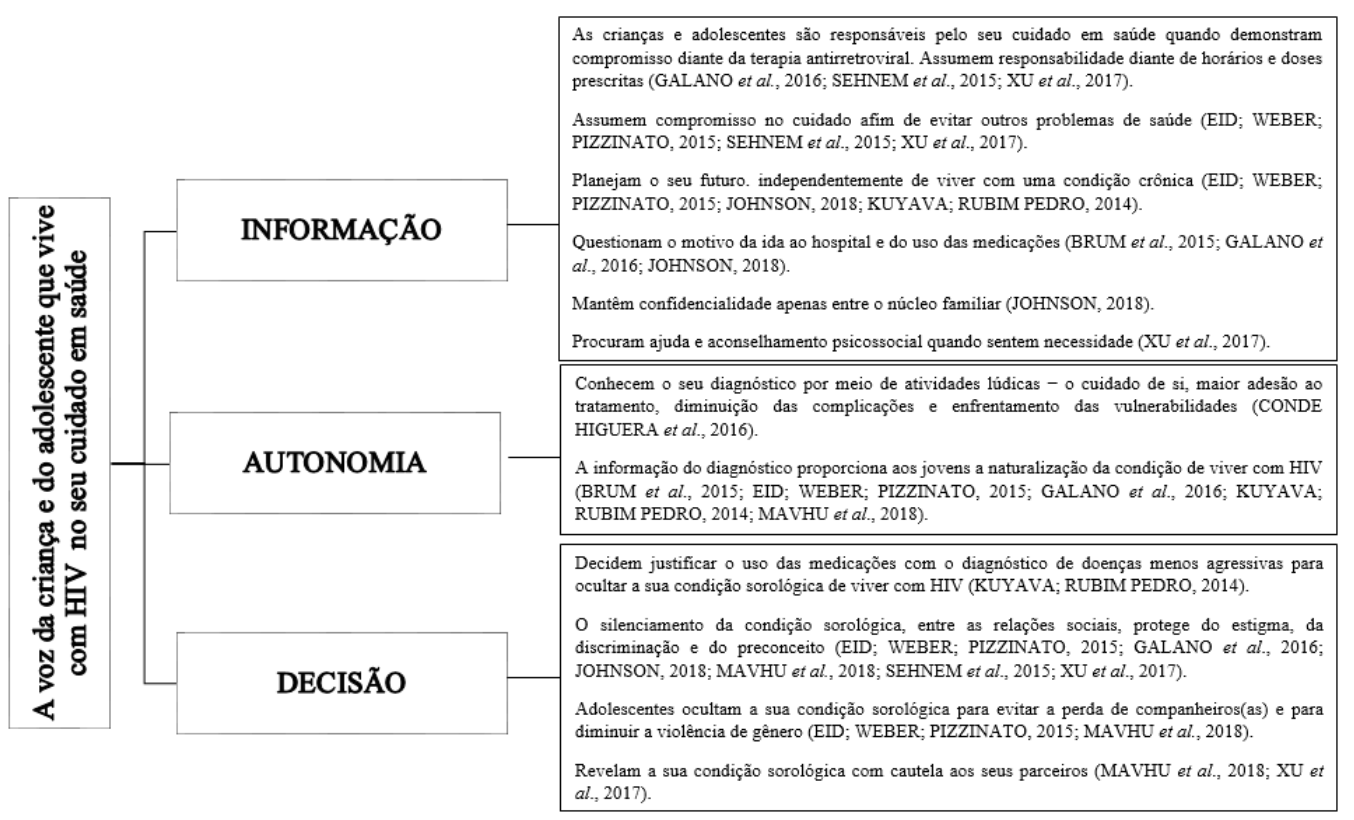

Fonte: elaborado pelos autores. Porto Alegre/RS, 2020.

A informação às crianças e aos adolescentes que vivem com HIV surge como uma estratégia para o cuidar de si, à medida que conhecem o diagnóstico, a necessidade de tratamento, a importância da adesão para diminuir complicações e ao fazerem frente às situações de vulnerabilidade inerentes à condição crônica (CONDE HIGUERA et al., 2016). Paralelamente, saber da sua condição de viver com um HIV parece que instala uma "sensação" de naturalização da situação para seguir o curso da vida (BRUM et al., 2015; EID; WEBER; PIZZINATO, 2015; GALANO et al., 2016; JOHNSON, 2018; KUYAVA; RUBIM PEDRO, 2014; XU et al., 2017).

Quando a informação é compreendida pelas crianças e pelos adolescentes que vivem com HIV, surge a autonomia, ao se responsabilizarem pelo tratamento, determinando horários e estratégias para tomar os medicamentos (GALANO et al., 2016; SEHNEM et al., 2015; XU et al., 2017) e assumindo o compromisso com o seu cuidado para prevenir problemas de saúde (EID; WEBER; PIZZINATO, 2015; SEHNEM et al., 2015; XU et al., 2017). A autonomia é percebida, também, ao problematizarem o uso contínuo da medicação e as frequentes visitas aos serviços de saúde (BRUM et al., 2015; GALANO et al., 2016; JOHNSON, 2018), ao expressarem o desejo de que a condição de viver com HIV seja mantida em segredo nos limites familiares 
(JOHNSON, 2018) e, ainda, ao se movimentarem para buscar apoio psicossocial (XU et al., 2017) e fazerem planos para o futuro (EID; WEBER; PIZZINATO, 2015; JOHNSON, 2018; KUYAVA; RUBIM PEDRO, 2014).

A participação das crianças e dos adolescentes que vivem com HIV, ou seja, a sua voz nas decisões em relação a sua saúde, é percebida quando optam em manter a informação em relação a sua condição sorológica no núcleo familiar (EID; WEBER; PIZZINATO, 2015; GALANO et al., 2016; JOHNSON, 2018; KUYAVA; RUBIM PEDRO, 2014; MAVHU et al., 2018; SEHNEM et al., 2015; XU et al., 2017), buscando proteger-se do estigma, da discriminação e do preconceito. Adolescentes decidem não revelar o seu status sorológico aos companheiros por medo do término da relação e de possíveis atitudes violentas (EID; WEBER; PIZZINATO, 2015; MAVHU et al., 2018), por vezes, inclusive, desconsiderando a necessidade de usar preservativo na relação sexual (JOHNSON, 2018; MAVHU et al., 2018; SEHNEM et al., 2015). Nesse ensejo, planejam a revelação do diagnóstico de forma cuidadosa aos parceiros (MAVHU et al., 2018; XU et al., 2017). Outra face que remete à participação na decisão é a justificativa do uso das medicações antirretrovirais com diagnósticos de doenças menos estigmatizadas (KUYAVA; RUBIM PEDRO, 2014). Inclusive, adolescentes grávidas decidem não aderir ao tratamento, mesmo que coloquem em risco seus filhos (JOHNSON, 2018).

\section{DISCUSSÃo}

Neste estudo, enfatiza-se o direito à participação nos cuidados em saúde que engloba o direito de ser ouvido, de ter sua percepção, vontade e preferências respeitadas. Estabelece o envolvimento na tomada de decisão acerca dos assuntos relacionados ao seu corpo e a sua saúde e proporciona que as crianças e os adolescentes tenham voz nos seus cuidados em saúde (ELER; ALBUQUERQUE, 2019a).

A criança e o adolescente são considerados indivíduos de direitos, tendo em vista o contexto da CDC, que instituiu ampla gama de direitos civis, políticos, econômicos, sociais e culturais. No entanto, verifica-se que a criança e o adolescente ocupam um papel secundário, por vezes, em relação à tomada de decisão em seu cuidado em saúde (GROOTENS-WIEGERS; HEIN; STAPHORST, 2018). 
Essa população não precisa ter um conhecimento exaustivo de todos os aspectos da decisão que a afeta, mas deve ter uma compreensão que seja suficiente para formar adequadamente um juízo sobre o assunto. A maturidade é entendida como a habilidade de compreender e avaliar as consequências de uma determinada decisão, ou seja, é a habilidade da criança e do adolescente de expressar suas opiniões sobre os assuntos de maneira razoável e independente, não sendo exigida a profundidade de compreensão (ELER; ALBUQUERQUE, 2019a).

A participação não significa, necessariamente, decidir. Deve-se considerar a criança e o adolescente como sujeitos ativos com as naturais limitações impostas pela idade. Participar é ter informações sobre a situação que os acomete, é compartilhar a responsabilidade pela decisão a ser tomada. O vínculo entre criança/adolescente, pais/responsáveis e equipe médica proporciona um cuidado pautado na dialogicidade e na concretização do melhor interesse para essa população (KONDER; TEIXEIRA, 2016).

Observa-se um crescente número de pesquisas científicas que apontam que as crianças, desde muito pequenas, têm capacidade de participar das decisões sobre sua saúde e de seus cuidados (ALDERSON; HAWTHORNE; KILLEN, 2006; COYNE et al., 2016; HEIN et al., 2015; RUHE et al., 2015). Sua participação é vista como benéfica, pois influencia positivamente em seu bem-estar, reduz o estresse associado ao tratamento e aos procedimentos, desenvolve o senso crítico, aumenta a confiança nos profissionais de saúde, melhora as habilidades de comunicação da criança, a eficácia dos serviços e os resultados do tratamento proposto (COYNE et al., 2014; 2016; RUHE et al., 2015). Outro estudo aborda que estabelecer parcerias e ouvir as vozes das crianças é um primeiro passo indispensável para aumentar e estimular a participação dessa população (GROOTENS-WIEGERS; HEIN; STAPHORST, 2018).

As pesquisas também demonstram que essa realidade de a criança ter respeitado seu direito de participar ainda é escassa. Visualiza-se, no cenário da saúde, que essa população ainda não é envolvida no planejamento ou nas decisões relativas aos seus cuidados e, mesmo quando expressa um desejo de envolvimento, não recebe suporte para concretizá-lo. Assim, as crianças ocupam uma posição marginal e passiva nas consultas, sendo as informações direcionadas aos responsáveis/familiares (COYNE, 2008; COYNE et al., 2014; COYNE; HOLMSTRÖM; SÖDERBÄCK, 2018). 
Cabe destacar que, em uma revisão de literatura, identificou-se que as crianças e os adolescentes são ignorados e desacreditados pelos profissionais da saúde e que sua participação é desestimulada e prejudicada pelos seguintes fatores: medo de causar problemas fazendo perguntas; falta de tempo e dificuldades para entrar em contato com os profissionais; desconhecimento de quem são os profissionais responsáveis; insegurança para entender a terminologia clínica; e atitudes dos pais, que interrompem ou mudam as respostas dos seus filhos, impedindo um comportamento participativo (COYNE, 2008).

Em uma pesquisa realizada na Irlanda com uma população de crianças com câncer, com o intuito de avaliar sua participação no seu cuidado em saúde, constatou-se que as principais decisões (investigações, tratamentos, exames) foram tomadas, em sua grande maioria, pelos profissionais de saúde e apenas discutidas com os familiares. A participação das crianças limitou-se a decisões secundárias referentes ao modo como os cuidados e os procedimentos seriam realizados, sem qualquer voz dessa população no tratamento escolhido. Nesse estudo, as crianças apontaram que ter voz no seu cuidado em saúde é receber informações, expressar suas preferências e ver que são levadas em conta, assim como negociar e escolher os tratamentos que seriam administrados (COYNE et al., 2014).

Em consonância com esses estudos, na revisão de literatura apresentada neste artigo, a participação das crianças e dos adolescentes não foi diferente. Não foram encontradas evidências científicas que relatassem a participação dessa população no seu cuidado em saúde, bem como sua inclusão no processo de tomada de decisão sobre as situações que lhe dizem respeito. As crianças e os adolescentes que vivem com HIV tiveram participação apenas em aspectos secundários, que tangenciam o seu cuidado em saúde, tornando-os ativos no momento em que vivenciaram algumas situações de informação, autonomia e decisão.

Portanto, observa-se que a informação proporcionou voz às crianças e aos adolescentes que vivem com HIV na medida em que adquiriram capacidade para cuidar de si. Por meio do conhecimento do diagnóstico da doença, do entendimento da necessidade do tratamento e da adesão a ele, vivenciam a naturalização de viver com uma condição crônica (BRUM et al., 2015; CONDE HIGUERA et al., 2016; EID; WEBER; PIZZINATO, 2015; GALANO et al., 2016; JOHNSON, 2018; KUYAVA; RUBIM PEDRO, 2014; XU et al., 2017). A ONU descreve que as crianças e os adolescentes devem receber informações sobre os tratamentos propostos, sobre 
seus efeitos e resultados, de maneira apropriada e acessível, para, assim, serem incluídas, efetivamente, na tomada de decisão e no manejo do seu cuidado (ONU, 2009).

A informação no contexto do cuidado em saúde deve ser abarcante, clara, transparente, e ter sentido para os envolvidos (SEHNEM et al., 2015; SPATZ; KRUMHOLZ; MOULTON, 2016). Esse processo de informar é reconhecido como um direito e configura-se como uma estratégia para diminuir a ansiedade, fortalecer a autoestima, assumir o autocontrole e contribuir na adesão ao tratamento da população de crianças e adolescentes (ELER; ALBUQUERQUE, 2019a; FLEISCHMANN, 2016; HARRISON, 2009), inclusive, os que vivem com HIV. Deve-se ofertar a essa população informações da sua condição de saúde, opções disponíveis de cuidados, bem como os benefícios do seu tratamento por meio de uma linguagem adequada, com o intuito de maximizar o seu bem-estar (ELER; ALBUQUERQUE, 2019a).

Não se pode deixar de relatar que existem estudos que demonstram que a criança é capaz de formar opiniões desde muito cedo, mesmo quando ainda não consegue expressá-las verbalmente. Por essa razão, ressalta-se que a aplicação do direito de participação por meio da informação requer o reconhecimento e o respeito de formas não verbais de comunicação, como a brincadeira, a expressão corporal e facial, o desenho e a pintura, por meio das quais as crianças demonstram a capacidade de compreender, escolher e ter preferências (ELER; ALBUQUERQUE, 2019b).

$\mathrm{O}$ direito à informação configura-se como essencial para que haja autonomia. A autonomia é entendida como elemento da dignidade humana que confere ao sujeito a faculdade de realizar escolhas acerca da sua própria vida e de conduzir-se conforme as mesmas (ALBUQUERQUE, 2018). Assim, no campo dos cuidados em saúde, a autonomia implica: direito à integridade corporal e direito de tomar decisões relacionadas aos seus cuidados em saúde.

Conforme os estudos analisados, as crianças e adolescentes possuíram voz quando demonstraram autonomia ao assumirem compromisso com o seu cuidado, responsabilidades pelo tratamento, determinação de horários e estratégias para tomar os medicamentos (GALANO et al., 2016; JOHNSON, 2018; SEHNEM et al., 2015), bem como quando questionaram sobre a necessidade dos mesmos (BRUM et al., 2015; GALANO et al., 2016; JOHNSON, 2018). Percebe-se autonomia, também, quando optam por manter segredo sobre a sua condição 
sorológica e, principalmente, quando fazem planos para o futuro (EID; WEBER; PIZZINATO, 2015; JOHNSON, 2018; KUYAVA; RUBIM PEDRO, 2014).

Nessa perspectiva, a participação da criança e do adolescente no seu cuidado em saúde proporciona o reconhecimento da sua autonomia, do seu processo de emancipação e da potencialização do seu desenvolvimento. Transforma a criança e o adolescente em coatores participativos da sua vida, ou seja, de terem seus desejos e interesses respeitados (ELER; ALBUQUERQUE, 2019b).

Percebe-se, nesta revisão, que as crianças e os adolescentes desenvolveram situações de decisão no seu cuidado em saúde. Sua voz foi respeitada quando decidiram manter a sua condição sorológica no núcleo familiar (EID; WEBER; PIZZINATO, 2015; GALANO et al., 2016; JOHNSON, 2018; KUYAVA; RUBIM PEDRO, 2014; MAVHU et al., 2018; SEHNEM et al., 2015; XU et al., 2017) e, no caso dos adolescentes, optaram por não revelar essa condição aos companheiros (EID; WEBER; PIZZINATO, 2015; ELER; ALBUQUERQUE, 2019b; MAVHU et al., 2018). Outra face que remete à participação na decisão dos seus cuidados é quando justificam o uso das medicações antirretrovirais com diagnósticos de doenças menos graves (KUYAVA; RUBIM PEDRO, 2014).

Os estudos selecionados não pontuaram como as situações secundárias de cuidado foram estimuladas, propostas e colocadas em prática pelos responsáveis e profissionais. Constata-se que o direito de participação é invisível no dia a dia dessa população nos serviços de saúde, e essas vozes aqui relatadas são consequências de aprender a viver com uma condição crônica como o HIV.

Essa invisibilidade pode ser justificada pelo fato de as políticas jurídicas não incluírem as crianças e os adolescentes na tomada de decisão em relação ao cuidado em saúde, na maioria das vezes, por declararem que eles não possuem capacidade de compreensão das informações. Outro ponto importante é que a comunicação oral e informações textuais são direcionadas aos adultos, o que dificulta o entendimento dessa população sobre sua condição de saúde e, assim, desfavorece a tomada de decisões (GROOTENS-WIEGERS; HEIN; STAPHORST, 2018).

Um estudo realizado na Suíça identificou aspectos que dificultam a participação da criança nas tomadas de decisões de seus cuidados em saúde. Tal estudo aponta os conflitos existentes entre os países sobre os conceitos e as terminologias, a discordância no que se 
refere à operacionalização e à mediação na tomada de decisão compartilhada, a inexistência de um instrumento que auxilie os profissionais a proporcionar a participação das crianças e a dificuldade de reconhecer os aspectos do desenvolvimento infantil (RUHE et al., 2015).

Outra situação é que as oportunidades de participação das crianças e dos adolescentes nos seus cuidados são bastante limitadas. Os familiares e os profissionais de saúde não consideram as muitas maneiras pelas quais essa população poderia ser envolvida (COYNE et al., 2014). Existem vários níveis de participação, desconhecidos por familiares e profissionais da saúde, como, por exemplo: quando a criança expressa o seu ponto de vista, seu desejo, tendo seus anseios respeitados; quando a criança e o adolescente possuem influência nas decisões; e quando a população é a principal tomadora de decisões (RUHE et al., 2015).

Portanto, torna-se extremamente difícil para uma criança e um adolescente adotar uma postura participativa em seus cuidados quando os profissionais permanecem com uma visão paternalista e desestimulam esse direito. Por essa razão, deve-se sustentar, cada vez mais, a inclusão das crianças e dos adolescentes na tomada de decisão em saúde, conforme a sua capacidade e o interesse em fazê-lo, para garantir que eles sejam rotineiramente ouvidos nos seus cuidados em saúde (OLSZEWSKI; GOLDKIND, 2018).

Para mudar esse cenário e para respeitar os direitos humanos nos cuidados em saúde, torna-se necessário investir na capacitação dos profissionais da saúde. Estes estão totalmente aliados ao processo de decisão, tendo em vista que são responsáveis por escutar e compreender as crianças e os adolescentes e, principalmente, por promover um cuidado que proporcionará voz à população de crianças e adolescentes. Ainda mais, destaca-se que o enfermeiro é considerado o profissional de referência em ouvir, não criticar ou julgar e desenvolver um cuidado com base nos direitos humanos (KUYAVA; RUBIM PEDRO, 2014).

É inaceitável que profissionais de saúde desconsiderem as obrigações oriundas das normas de direitos humanos que concedem às crianças e aos adolescentes sua participação ativa em seus cuidados. Sabe-se que há uma lacuna na formação desses profissionais quanto aos conteúdos de direitos humanos, o que ocasiona a não implementação e incorporação de avanços dessa prática nos serviços de saúde. Diante disso, registra-se a necessidade de reconfigurar a formação na área da saúde, a fim de que o profissional se perceba como um agente importante na promoção dos direitos da criança e do adolescente e, principalmente, 
no entendimento de que direito de participar garante qualidade nos cuidados em saúde para a população infanto-juvenil (ELER; ALBUQUERQUE, 2019a).

Dessa forma, considera-se relevante o desenvolvimento de pesquisas científicas nos contextos brasileiro e internacional, com o intuito de subsidiar intervenções que fomentem a participação das crianças e dos adolescentes em seus cuidados em saúde (COYNE et al., 2016; KEW et al., 2017; MALONE et al., 2019).

\section{CONSIDERAÇÕES FINAIS}

Acredita-se que esta revisão constitui um caminho para explanar sobre a temática referente à participação de crianças e adolescentes que vivem com HIV quanto aos cuidados com sua saúde. As evidências científicas encontradas revelam que essa população possui voz em aspectos secundários e pontuais, ou seja, em estratégias de cuidado ao se viver com HIV.

Este estudo proporciona uma reflexão sobre a importância de respeitarmos o direito à participação de crianças e adolescentes como um direito humano nos cuidados em saúde. Sabe-se que, por mais que a CDC tenha sido discutida anos atrás, seu conhecimento e sua implementação ainda são algo incipiente e novo no cenário da prática clínica e das pesquisas científicas. Assim, este estudo colabora, principalmente, ao propiciar uma reflexão para profissionais, familiares, cuidadores e, até mesmo, para crianças e adolescentes, sobre a relevância de considerar e conhecer o direito de participação destes nos cuidados em saúde.

Como lacuna do estudo, não foi identificada nenhuma evidência que discorra sobre a implementação, importância e respeito ao direito de participação dessa população. Contudo, observa-se que os aspectos encontrados, ou seja, sua participação por meio da informação, autonomia e decisão contribuem positivamente no viver com HIV.

Por fim, os profissionais da saúde necessitam reconhecer a criança e o adolescente que vivem com HIV enquanto protagonistas do seu cuidado em saúde para que adiram mais facilmente ao tratamento, melhorando a eficácia deste e, consequentemente, o bem-estar da referida população.

$\mathrm{Na}$ análise dos estudos da presente revisão integrativa, observa-se a prevalência de pesquisas com abordagem qualitativa. Isso leva a concluir que existe a necessidade de investir 
em estudos que utilizem métodos para aplicar e fortalecer as evidências científicas como estudos clínicos e metassíntese.

\section{FINANCIAMENTO}

O presente trabalho contou com o apoio da Coordenação de Aperfeiçoamento de Pessoal de Nível Superior - Brasil (CAPES) - Código de Financiamento 001.

\section{REFERÊNCIAS}

ALBUQUERQUE, A. Ombudsman do paciente: direitos nos cuidados em saúde. Revista Bioética, v. 26, n. 3, p. 326-332, 2018. Disponível em: <https://www.ghc.com.br/files/Ombudsman.pdf >. Acesso em: 4 de abril de 2019.

ALDERSON, P.; HAWTHORNE, J.; KILLEN, M. The participation rights of premature babies. Children's Health and Children's Rights, p. 31-50, 2006. Disponível em: $<$ https://brill.com/view/book/edcoll/9789047408697/Bej.9789004148949.i-337_004.xml>. Acesso em: 11 de janeiro de 2019.

BRAGA, R. M. DE O.; LIMA, T.P.; GOMES, A.M.T.; OLIVEIRA, D.C.; SPINDOLA, T.; MARQUES, S.C. Representações sociais do HIV/AIDS para as pessoas que convivem com a síndrome. Revista Enfermagem Uerj, v. 24, n. 2, p. 16, 2016. Disponível em: <http://www.facenf.uerj.br/v24n2/v24n2a05.pdf>. Acesso em: 5 de junho de 2019.

BRASIL. LEI no 8.069, de 13 de julho de 1990. Dispõe sobre o Estatuto da Criança e do Adolescente e dá outras providências. 1990. Disponível em: <http://www.planalto.gov.br/ccivil_03/leis/l8069.htm>. Acesso em: 8 de fevereiro de 2019.

BRUM, C. N. DE.; PAULA, C.C.DE.; PADON, S.M.DE.; SOUZA, I.E.DE OLIVEIRA.; NEVES, E.T.; ZUGE, S.S. Disclosure of the HIV diagnosis to the teenager: ways of being everyday. Escola Anna Nery - Revista de Enfermagem, v. 19, n. $4, \quad$ p. $479-684, \quad 2015 . \quad$ Disponível em: <http://www.scielo.br/scielo.php?pid=S141481452015000400679\&script=sci_arttext\&tlng=en>. Acesso em: 5 de junho de 2019.

CARNEVALE, F. Ethical considerations in pediatric nursing. Revista da Sociedade Brasileira de Enfermagem Pediátrica [Internet], v. 12, n. 1, p. 37-47, 2012. Disponível em: <https://sobep.org.br/revista/component/zine/article/152-ethical-considerations-inpediatric-nursing.html>. Acesso em: 9 de outubro de 2019.

CARNEVALE, F. A.; BUBADUÉ, R.DE MOURA.; FONSECA, E.M.; SANTO, A.E.; CABRAL, I.E. Análise normativa dos padrões éticos para crianças no Brasil. Revista da SORBI, v. 2, n. 1, p. 35-55, 2014. Disponível em: <http://www.sorbi.org.br/revista/index.php/revista_sorbi/article/view/21>. Acesso em: 4 de abril de 2019.

CONDE HIGUERA, P.; RAMIREZ, M.L.P.; ÁVILLA, A.D.; MORATALLA, T.D. Estigma, discriminación y adherencia al tratamiento en niños con VIH y SIDA: Una perspectiva bioética. Acta bioethica, v. 22, n. 2, p. 331-340, 2016. Disponível em: <https://scielo.conicyt.cl/scielo.php?script=sci_arttext\&pid=\$1726-569X2016000200020>. 
Acesso em: 26 de setembro de 2019.

COYNE, I. Children's participation in consultations and decision-making at health service level: A review of the literature. International Journal of Nursing Studies, v. 45, n. 11, p. 1682-1689, 2008. Disponível em: <https://www.sciencedirect.com/science/article/abs/pii/S0020748908001466>. Acesso em: 13 de setembro de 2019.

COYNE, I.; AMOTY, A.; KIERMAN, G.; GIBSON, F. Children's participation in shared decision making: Children, adolescents, parents and healthcare professionals' perspectives and experiences. European Journal of Oncology Nursing. Elsevier Ltda, v. 18, n. 3, p. 273-280, 2014. Disponível em: <https://www.ncbi.nlm.nih.gov/pubmed/24629505> Acesso em: 20 de agosto de 2019.

COYNE, I.; O'MATHÚNA, D.P.; GIBSON, F.; SHIELDS, L.; LACLERCQ, E.; SHEAF, G. Interventions for promoting participation in shared decision-making for children with cancer. Cochrane Database of Systematic Reviews, v. 2016, n. $11,2016 . \quad$ Disponível em: <https://www.cochranelibrary.com/cdsr/doi/10.1002/14651858.CD008970.pub3/abstract>. Acesso em: 8 de outubro de 2019.

COYNE, I.; HOLMSTRÖM, I.; SÖDERB ÄCK, M. Centeredness in Healthcare: A Concept Synthesis of Family-centered Care, Person-centered Care and Child-centered Care. Journal of Pediatric Nursing, v. 42, p. 45-56, 2018. Disponível em: <https://linkinghub.elsevier.com/retrieve/pii/S0882-5963(18)30176-3>. Acesso em: 8 de outubro de 2019.

EID, A. P.; WEBER, J. L. A. W.; PIZZINATO, A. P. Maternity and life plans among young people infected with HIV by vertical transmission. Revista Latinoamericana de Ciencias Sociales, Niñez y Juventud, v. 13, n. 2, p. 937950, 2015. Disponível em: <http://www.scielo.org.co/scielo.php?script=sci_arttext\&pid=S1692715X2015000200028>. Acesso em: 4 de novembro de 2019.

ELER, K.; ALBUQUERQUE, A. Direito à participação da criança nos cuidados em saúde sob a perspectiva dos Direitos Humanos dos Pacientes. Revista Iberoamericana de Bioética, n. 9, p. 1-15, 2019a. Disponível em: <http://docs.bvsalud.org/biblioref/2019/05/996355/03_dh-crianca.pdf>. Acesso em: 6 de outubro de 2019.

ELER, K.; ALBUQUERQUE, A. Direitos humanos da paciente criança. Cadernos Ibero-Americanos de Direito Sanitário, v. $\quad 8, \quad$ n. $\quad 1, \quad$ p. $\quad 36, \quad 2019 \mathrm{~b}$. Disponível el <https://www.cadernos.prodisa.fiocruz.br/index.php/cadernos/article/view/509>. Acesso em: 6 de outubro de 2019.

FLEISCHMAN, Alan R. Pediatric ethics: protecting the interests of children. New York: Oxford, 2016.

GALANO, E.; TURATO, E.R.; DELMAS, P.; CÔTE, J.; GOUVEA, A.F.R.B.; SUCCI, R.C.M.; MACHADO, D.M. Vivências dos adolescentes soropositivos para HIV/Aids: estudo qualitativo. Revista Paulista de Pediatria, v. 34, n. 2, p. 171177, 2016. Disponível em: <http://www.scielo.br/scielo.php?pid=S010305822016000200171\&script=sci_arttext\&tlng=pt>. Acesso em: 8 de novembro de 2019.

GROOTENS-WIEGERS, P.; HEIN, I.; STAPHORST, M. Using Children's Voice to Optimize Pediatric Participation in Medical Decision Making. American Journal of Bioethics, v. 18, n. 3, p. 14-16, 2018. Disponível em: <https://www.tandfonline.com/doi/full/10.1080/15265161.2017.1418928>. Acesso em: 8 de novembro de 2019.

HARRISON C. Truth telling in pediatric: What they don't know might hurt them. In: Miller G, editor. Pediatric Bioethics. New York: Cambridge University Press, v.1, n.1, p. 73-86, 2009.

HEIN, I. M.; VRIES, M.C.; TROOST, P.W.; MEYNEN, G. Informed consent instead of assent is appropriate in children from the age of twelve: Policy implications of new findings on children's competence to consent to clinical research Ethics in Public Health, medical law, and health policy. BMC Medical Ethics, v. 16, n. 1, p. 1-7, 2015. Disponível em: <https://bmcmedethics.biomedcentral.com/articles/10.1186/s12910-015-0067-z>. Acesso em: 8 de outubro de 2019 .

JOHNSON, E. J. A case study on the consequences of HIV/AIDS within the Caribbean: Issues faced by a teenager 
born with HIV. HIV and AIDS Review, v. 17, n. 2, p. 152-157, 2018. Disponível em: <https://www.termedia.pl/Acase-study-on-the-consequences-of-HIV-AIDS-within-the-Caribbean-issues-faced-by-a-teenager-born-withHIV,106,33009,1,1.html>. Acesso em: 10 de outubro de 2019.

KEW, K.; MALIK, P.; ANIRUDDHAN, K.; NORMANSELI, R. Shared decision-making for people with asthma (Review). Cochrane Database of Systematic Reviews, n. 10, 2017. Disponível em: <https://www.ncbi.nlm.nih.gov/pmc/articles/PMC6485676/pdf/CD012330.pdf>. Acesso em: 5 de setembro de 2019.

KONDER, C.N.N; TEIXEIRA, A.C.B. Crianças e adolescentes na condição de pacientes médicos: desafios da ponderação entre autonomia e vulnerabilidade. Pensar, v. 21, n. 1, p. 70-93, 2016. Disponível em: <https://periodicos.unifor.br/rpen/article/view/4185>. Acesso em: 20 de agosto de 2019.

KUYAVA, J.; RUBIM PEDRO, E. N. The voice of children who live with HIV on implications of the disease in their daily life. Investigación y Educación en Enfermería, v. 32, n. 2, p. 317-325, 2014. Disponível em: <http://www.scielo.org.co/scielo.php?script=sci_abstract\&pid=S0120-53072014000200014>. Acesso em: 9 de agosto de 2019.

MALONE, H.; BIGGAR, S.; JAVADPOUR, SP.; EDWORTHY, Z.; CHEAF, G.; COYNE, I. Interventions for promoting participation in shared decisionmaking for children and adolescents with cystic fibrosis. Cochrane Database of Systematic Reviews, v. 2019, n. 5, 2019. Disponível em: <https://www.ncbi.nlm.nih.gov/pubmed/31119726>. Acesso em: 7 de agosto de 2019.

MAVHU, W.; ROWLEY, E.; THIOR, I.; KRUSE-LEVY, N.; MUGURUNGI, O.; NCUBE, G.; LECLERC-MADIALA, S. Sexual behavior experiences and characteristics of male-female partnerships among HIV positive adolescent girls and young women: Qualitative findings from Zimbabwe. PLoS ONE, v. 13, n. 3, p. 1-11, 2018. Disponível em: <https://www.ncbi.nlm.nih. /pubmed gov /29566062>. Acesso em: 8 de setembro de 2019.

MENDES, K. D. S.; SILVEIRA, R. C. DE C. P.; GALVÃO, C. M. Revisão integrativa: método de pesquisa para a incorporação de evidências na saúde e na enfermagem. Texto \& Contexto - Enfermagem, v. 17, n. 4, p. 758764, 2008. Disponível em: <http://www.scielo.br/scielo.php?script=sci_arttext\&pid=S0104 07072008000400018>. Acesso em: 18 de novembro de 2019.

MOHER, D.; LIBERATI, A.; TETZLAFF, J.; ALTMAN, D.G. PRISMA Group. Preferred reporting items for systematic reviews and meta-analyses: the PRISMA statement. Plos med [on-line], 2009. Disponível em: <https://journals.plos.org/plosmedicine/article?id=10.1371/journal.pmed.1000097\#s4>. Acesso em: 15 de Setembro de 2019.

OLSZEWSKI, A.E.; GOLDKIND, S.F. The Default Position: Optimizing Pediatric Participation in Medical Decision Making. The American Journal of Bioethics, v. 18, n. 3, p. 4-9, 2018. Disponível em: <https://www.tandfonline.com/doi/abs/10.1080/15265161.2017.1418921?journalCode=uajb20>. Acesso em: 28 de novembro de 2019.

ONU. Assembleia Geral das Nações Unidas. Convenção sobre os Direitos da Criança. 1989. Disponível em: $<$ https://www.unicef.org/brazil/convencao-sobre-os-direitos-da-crianca>. Acesso em: 7 de janeiro de 2019.

ONU. Assembleia Geral das Nações Unidas. Committee on the Rights of the Child (CRC), General comment No. 3 (2003): HIV/AIDS and the Rights of the Child. 2003. Disponível em: <https://www.refworld.org/docid/4538834e15.html>. Acesso em: 7 de janeiro de 2019.

ONU. Assembleia Geral das Nações Unidas. General Comment $\mathbf{n}^{\circ} \mathbf{1 2}$. The right of the child to be heard [Internet]. Commitee on the Rights of the Child. 2009. Disponível em: https://www2.ohchr.org/english/bodies/crc/docs/AdvanceVersions/CRC-C-GC-12.pdf

. Acesso em: 8 de janeiro de 2019.

RUHE, K. M.; WANGMO, T.; BADARAU, D.O.; ELGER, B.S.; NIGGLI, F. Decision-making capacity of children and adolescents-suggestions for advancing the concept's implementation in pediatric healthcare. European Journal of Pediatrics, v. 174, n. 6, p. 775-782, 2015. Disponível em: 
<https://www.ncbi.nlm.nih.gov/pubmed/25425521>. Acesso em: 3 de dezembro de 2019.

SEHNEM, G. D.; BRONDANI, J.P.; KANTORSKI, K.J.C.; SILVA, S.C.; RESSEL, L.B.; PEDRO, E.N.R. A saúde no adolescer com HIV / aids : caminhos para uma agenda pós-2015. Revista Gaúcha de Enfermagem, v. 36, p. 39-46, 2015. Disponível em: <http://www.scielo.br/scielo.php?pid=\$1983-

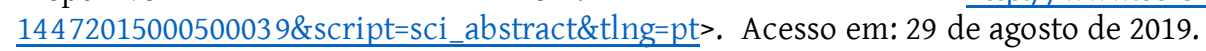

SPATZ E.S; KRUMHOLZ H.M; MOULTON B.W. The new era of informed consent: Getting to a reasonable-patient standard through shared decision making. Jama, v.6, n.7, 2016.2 Disponível em: <https://www.ncbi.nlm.nih.gov/pmc/articles/PMC5459384/>. Acesso em 25 de agosto de 2019.

XU, L.; MUNIR, K.; KANABKAEW, C.; LE COEUR, S. Factors influencing antiretroviral treatment suboptimal adherence among perinatally hiv infected adolescents in Thailand. PLOS ONE, v. 12, n. 2, p. 1-18, 2017. Disponível em: <https://www.ncbi.nlm.nih.gov/pubmed/28207891>. Acesso em: 16 de novembro de 2019.

(c) E EY

Este trabalho está licenciado com uma Licença Creative Commons - Atribuição 4.0 Internacional. 